\title{
PERFIL AMBIENTAL QUALITATIVO DE UMA MARCENARIA NA CIDADE DE VIÇOSA, MG
}

\author{
Michele Karina Cotta Walter ${ }^{1}$, Ricardo Ribeiro Alves ${ }^{2}$, Elias Silva ${ }^{3}$, \\ Laércio Antônio Gonçalves Jacovine ${ }^{3}$, Naisy Silva Soares ${ }^{4}$, Eliana Boaventura Bernardes Moura ${ }^{5}$ \\ ${ }^{1}$ Eng ${ }^{\mathrm{a}}$ Florestal, Doutoranda em Engenharia Agrícola, UNICAMP - mkcotta@ yahoo.com.br \\ ${ }^{2}$ Administrador, Dr., UNIPAMPA - ricardoalves@ unipampa.edu.br \\ ${ }^{3}$ Eng. Florestal, Dr., Depto. Engenharia Florestal, UFV - eshamir@ufv.br; jacovine@ufv.br \\ ${ }^{4}$ Economista, Dr., UESC - naisysilva@ yahoo.com.br \\ ${ }^{5}$ Acadêmica de Engenharia Florestal, UFV - eliana_boaventura@yahoo.com.br \\ Recebido para publicação: 08/09/2009 - Aceito para publicação: 18/04/2011
}

\begin{abstract}
Resumo
O ramo de marcenaria se insere no setor florestal, sendo que diversos impactos positivos e negativos advêm desse tipo de indústria. Assim, o presente estudo teve como objetivo avaliar o perfil ambiental qualitativo de uma marcenaria na cidade de Viçosa, Minas Gerais. A identificação e a caracterização dos impactos ambientais foram realizadas utilizando-se o método do "check-list" e a avaliação qualitativa dos impactos por meio do método das matrizes de interação. Foram identificadas treze atividades impactantes referentes à fase de operação da marcenaria. A maioria dos impactos foi classificada como Negativo, Direto, Local, de Médio Prazo, Temporário e Reversível (NDLMTV), estando $41 \%$ relacionados ao meio físico, $35 \%$ ao meio biótico, e $24 \%$ ao meio antrópico. Foram delineadas 39 medidas mitigadoras e potencializadoras para o empreendimento. Conclui-se que os impactos ambientais identificados na marcenaria podem ser mitigados ou potencializados por meio de ações relativamente simples, visto que foram classificados, na maior parte dos casos, como temporários e reversíveis.

Palavras-chave: Impacto ambiental; meio ambiente; produção de móveis.
\end{abstract}

\begin{abstract}
Qualitative environmental profile of a joinery company at Viçosa, MG. The branch of joineries is one of activities impacting on the forestry sector. Several positive and negative impacts arise from this kind of industry. This study aimed to evaluate the environmental quality profile of a joinery company in the city of Viçosa, Minas Gerais. The identification and characterization of the environmental impacts were done according to the "check-list 'and qualitative assessment of impacts using the method of interaction matrices. We identified fifteen impacting activities on the stage of operation of the woodwork. Most of the impacts were classified as a negative impact, Direct, Local, Medium Term, Temporary and Reversible (NDLMTV), as well as $41 \%$ related to physical environment, $35 \%$ to biota, and $24 \%$ to man. We outlined 39 mitigating and potential actions to the venture. It concludes that environmental impacts identified in joinery can be mitigated or enhanced by relatively simple actions, which had been classified in a large amount of situations as temporary and reversible.

Keywords: Environmental impact; environment; furniture production.
\end{abstract}

\section{INTRODUÇÃO}

A questão ambiental tem sido bastante discutida na mídia e em vários setores da sociedade. Essa discussão chegou às empresas, que passaram a ser cobradas por suas ações de responsabilidade perante a comunidade, tanto em termos ambientais quanto sociais. A escassez dos recursos naturais, as exigências dos órgãos ambientais e trabalhistas e a crescente conscientização da população são os atuais desafios enfrentados pelas empresas, o que faz com que elas, segundo Coutinho e Soares (2002), sintam pressões para adotar posturas socialmente responsáveis na condução dos seus negócios.

O compromisso das empresas para com o meio ambiente deixou de ser somente um atendimento à legislação e se transformou numa responsabilidade ética para com a sociedade. Em alguns setores 
produtivos, é exigido o licenciamento ambiental como forma de enquadrar as organizações dentro de padrões aceitáveis de cumprimento de requisitos ambientais. Uma postura esperada das empresas, nessa nova conjuntura, é a minimização dos impactos ambientais negativos de suas atividades.

Entre as atividades desenvolvidas pela cadeia florestal, a marcenaria tem contribuído para a geração de impactos positivos e negativos ao meio ambiente. Tal atividade é caracterizada pela reunião de diversos processos produtivos, envolvendo o uso de diferentes matérias-primas, que implicam a geração de impactos ambientais, os quais devem ser identificados e avaliados. Para Bovea e Vidal (2004), conhecer os impactos ambientais negativos decorrentes do uso de matéria-prima e do processo produtivo, em qualquer atividade, e desenvolver ações para minimizá-los, permite às empresas uma produção sustentável, além de agregação de valor aos seus produtos, acelerando assim sua introdução no emergente mercado de produtos verdes ou ecológicos.

No município de Viçosa, localizado na Zona da Mata mineira e próximo ao Polo Moveleiro de Ubá, a indústria de móveis representa uma atividade importante na economia local, atendendo públicos diversos, segundo sua posição social. No entanto, de acordo com Alves et al. (2008), a indústria moveleira de Viçosa apresenta características bem diferentes das do Polo Moveleiro de Ubá e não aproveita as vantagens oferecidas para alavancar seu desenvolvimento e produção.

Considerando as características do processo produtivo da atividade de marcenaria e a possibilidade de tal atividade gerar impactos positivos e negativos aos meios físico, biótico e antrópico, a hipótese deste trabalho é que, identificando e avaliando qualitativamente esses impactos, possam ser propostas medidas relativamente simples e viáveis para mitigá-los ou potencializá-los.

De acordo com o exposto, o objetivo geral deste estudo foi avaliar o perfil ambiental, de forma qualitativa, de uma marcenaria na cidade de Viçosa (MG). Os objetivos específicos incluem: identificar e descrever as atividades impactantes do empreendimento; identificar e caracterizar os principais impactos ambientais da atividade utilizando o método do "check-list"; avaliar qualitativamente os impactos ambientais por meio do método da matriz de interação; propor medidas mitigadoras para os impactos negativos e potencializadoras para os impactos positivos.

\section{MATERIAL E MÉTODOS}

\section{Caracterização do empreendimento}

O estudo foi realizado em uma marcenaria de pequeno porte, localizada na cidade de Viçosa, estado de Minas Gerais. Segundo estudos de Alves et al. (2008), essa marcenaria se enquadra no perfil de pequeno porte desse tipo de empreendimento encontrado na cidade, caracterizado por utilizar madeira maciça na fabricação dos móveis, possuir mão de obra pouco qualificada, maquinário antigo e obsoleto e apresentar pequena diversificação em sua linha de produtos. A estrutura física da marcenaria é composta por um galpão em forma de "L", dividido em 10 cômodos, incluindo: escritório, cantina, sanitário, almoxarifado, galpão de despejo, depósito e salas onde se encontram dispostos os maquinários e são realizadas as operações para fabricação de uma variedade de produtos, dentre eles móveis residenciais, de escritórios e utensílios para propriedades rurais.

No início de suas atividades, a marcenaria utilizava madeiras extraídas de reservas florestais da região, mas, posteriormente, passou a adquirir também madeira serrada, compensado, chapa de aglomerado e insumo de fornecedores externos. A mão de obra utilizada é considerada de baixa qualificação, pois não há um programa de treinamento sistematizado para os funcionários, inclusive com relação à prevenção de acidentes e manutenção de equipamentos.

\section{Identificação e descrição das atividades impactantes}

Atividades impactantes são as ações desenvolvidas no sentido de implantar e conduzir os empreendimentos impactantes (SILVA, 1999). No presente estudo, foram identificadas as atividades impactantes relacionadas à fase de operação da marcenaria. Para se proceder a identificação e descrição dessas atividades, foram realizadas consultas a referências bibliográficas e visitas ao local, onde foram feitas entrevistas com os funcionários, o acompanhamento in loco do processo produtivo e a identificação das interferências desse processo nos meios físico, biótico e antrópico.

Foram identificadas treze atividades impactantes, as quais são descritas a seguir: 
Contratação de mão de obra: refere-se à contratação de funcionários administrativos e operacionais para trabalhar nas atividades de gerenciamento e produção dos móveis.

Aquisição da matéria-prima: trata-se da compra, por parte da marcenaria, da matéria-prima necessária no processo produtivo, tais como madeiras, compensados, pregos, parafusos, colas, adesivos, solventes, vernizes etc.

Disposição da matéria-prima: implica a acomodação nem sempre adequada das peças de madeira e dos produtos químicos na área do empreendimento.

Funcionamento das máquinas: são utilizados diferentes tipos de maquinários, movidos principalmente à energia elétrica nas diferentes etapas do processo produtivo.

Processamento da madeira pelo uso das máquinas: essa atividade inclui corte, desengrosso, desempeno, fresamento e modelagem das chapas e peças de madeira.

Manutenção de equipamentos e reposição de peças: o uso intensivo de maquinários e a manutenção de lâmpadas acesas implicam alto consumo de energia elétrica.

Uso de produtos químicos: produtos químicos, como colas, solventes, tintas, ceras, seladores e vernizes são utilizados na colagem, coloração e acabamento das peças de madeira.

Aproveitamento das sobras operacionais: parte dos resíduos de madeira, tais como cascas, cavacos, serragens e lascas são aproveitados para geração de energia e destinados a granjas.

Descarte de resíduos de madeira com resquícios químicos: resíduos de madeira contendo resquícios de produtos químicos são dispostos, juntamente com outros tipos de resíduos, na área interna e externa do galpão da marcenaria.

Descarte de embalagens: embalagens plásticas, vidros, latas, papel e papelões são descartados conjuntamente, sem preocupação com coleta seletiva.

Disposição dos resíduos: não há um sistema definido para disposição dos resíduos oriundos do processo produtivo, tais como pó de serra e maravalhas, nem mesmo para as embalagens plásticas, papelóes, latas, vidros etc., na medida em que são ajuntados sem maiores preocupações.

Queima dos resíduos: é realizada a queima de alguns resíduos de madeira (pó de serra) e de embalagens na parte externa do galpão da marcenaria.

Geração de efluentes e resíduos domésticos: efluentes domésticos são gerados pelos funcionários, em vista da cocção de alimentos no ambiente de trabalho. Além disso, resíduos domésticos são gerados pelos funcionários, sendo que não há um sistema adequado de disposição dos mesmos.

\section{Identificação, caracterização qualitativa e descrição dos impactos ambientais}

O Conselho Nacional do Meio Ambiente (CONAMA), por meio da Resolução $n^{\circ} 1$, de 23 de janeiro de 1986, definiu impacto ambiental como qualquer alteração das propriedades físicas, químicas e biológicas do meio ambiente, causadas por qualquer forma de matéria ou energia resultante das atividades humanas que, direta ou indiretamente, afetam a saúde, a segurança e o bem-estar da população; as atividades sociais e econômicas; a biota; as condições estéticas e sanitárias do meio ambiente; e a qualidade dos recursos ambientais (BRASIL, 1986).

A identificação, caracterização qualitativa e descrição dos impactos ambientais da marcenaria foram feitas utilizando-se os métodos da Matriz de Interação e da Listagem de Controle ou "check-list", descritos em Moreira (1985) e Silva (1994). Segundo esses autores, o método da Matriz de Interação utiliza uma figura para relacionar os impactos de cada ação com o fator ambiental a ser considerado, a partir de quadrículas definidas pelo cruzamento de linhas e colunas. Funcionam como listagens de controle bidimensionais, em que as linhas representam as ações impactantes, e as colunas os fatores ambientais. As matrizes podem ser qualitativas, quando são usados os critérios de classificação qualitativa de impactos ambientais, ou quantitativas, quando são utilizados critérios relativos à magnitude dos impactos, por meio de uso de números (notas) ou cores. O método do "check-list" consiste na listagem dos impactos ambientais quando se considera a capacidade transformadora do ambiente físico, biótico e antrópico, sob o aspecto positivo e negativo, de causas (atividades impactantes) conhecidas. Optou-se neste estudo por utilizar o "check-list" descritivo, método também utilizado e recomendado por Silva (1994), Arruda (2000), Brito et al. (2002) e Lelles et al. (2005).

Inicialmente, aplicou-se a matriz de interação, com cada atividade impactante sendo caracterizada qualitativamente em relação aos fatores ambientais relacionados aos meios físico, biótico e antrópico, considerando os seguintes critérios definidos por Silva (1994): 
Critério de Valor: impacto positivo ou benéfico (quando uma ação causa melhoria da qualidade de um fator ambiental) e impacto negativo ou adverso (quando uma ação causa um dano à qualidade de um fator ambiental);

Critério de Ordem: impacto direto (quando resulta de uma simples relação de causa e efeito) e impacto indireto (quando é uma reação secundária em relação à ação ou quando é parte de uma cadeia de reações); Critério de Espaço: impacto local (quando a ação circunscreve-se ao próprio sítio e às suas imediações), impacto regional (quando o impacto se propaga por uma área além das imediações do sítio onde se dá a reação) e impacto estratégico (quando é afetado um componente ambiental de importância coletiva);

Critério de Tempo: impacto em curto prazo, impacto em médio prazo e impacto em longo prazo;

Critério de Dinâmica: impacto temporário (quando o impacto permanece por um tempo determinado, após a realização da ação), impacto cíclico (quando o impacto se faz sentir em determinados ciclos, que podem ser ou não constantes ao longo do tempo), impacto permanente (quando, uma vez executada a ação, os impactos não param de se manifestar num horizonte temporal conhecido);

Critério de Plástica: impacto reversível (quando, uma vez cessada a ação, o fator ambiental retorna às suas condições originais) e impacto irreversível (quando, cessada a ação, o fator ambiental não retorna às suas condições originais, considerando um horizonte de tempo aceitável pelo homem).

O método do "check-list", por sua vez, foi utilizado para complementação, no sentido de explicitar analiticamente os impactos detectados na matriz de interação. Depois de identificados e descritos os impactos ambientais da atividade, foram propostas medidas mitigadoras e potencializadoras para os impactos considerados negativos e positivos, respectivamente.

\section{RESULTADOS E DISCUSSÃO}

\section{Identificação e caracterização qualitativa dos impactos ambientais}

A caracterização qualitativa dos impactos ambientais pela matriz de interação é apresentada na tabela 1. Entre as 156 possíveis interações entre atividades impactantes e fatores ambientais do meio físico, biótico e antrópico, foi possível identificar e classificar qualitativamente 34 delas. De acordo com os critérios utilizados para qualificação dos impactos gerados, verificou-se que a maior parte foi classificada como Impacto Negativo, Direto, Local, de Médio Prazo, Temporário e Reversível (NDLMTV), estando $41 \%$ relacionados ao meio físico, $35 \%$ ao meio biótico e $24 \%$ ao meio antrópico.

$\mathrm{O}$ fato de o meio físico ser o mais impactado é atribuído à não existência de exaustores no local e de um sistema adequado de gerenciamento de resíduos industriais e domésticos, visto que uma das características desse tipo de atividade é a emissão de pó de serra durante o processo produtivo e a geração de resíduos, como cavacos de madeira, maravalhas e serragem, além de embalagens de papel, plástico, vidros e latas com e sem resquícios de produtos químicos. Nesse sentido, Venzke; Nascimento (2002) sugerem ações que tendem a melhorar o destino dado aos resíduos desse tipo de atividade, tais como: melhor aproveitamento da serragem e cavacos de madeira, utilizando-os, por exemplo, para a fabricação de painéis de madeira aglomerada; reaproveitamento das embalagens, seja pela reutilização, seja pela reciclagem; e adoção de um programa para a redução dos resíduos gerados, pois, numa visão ambiental mais ampla, melhor do que dar um destino adequado aos resíduos é não gerá-los.

A influência das atividades impactantes da marcenaria ao meio biótico é atribuída à localização do empreendimento, que é próximo a um remanescente de mata nativa, onde existe uma variedade de espécies animais e vegetais. $\mathrm{O}$ funcionamento das máquinas causa afugentamento de animais. A emissão de pó de serra, da fumaça oriunda da queima de resíduos e a disposição inadequada de resíduos químicos no solo podem provocar danos à vegetação. Além desses, outro fator impactado no meio biótico é o comprometimento dos recursos naturais, visto que a maior parte da madeira utilizada na marcenaria é maciça, de espécies nativas e sem comprovação de procedência. Em menor quantidade, são utilizadas madeira de Pinus, painéis, laminados, compensado e MDF. Alves et al. (2008) justificaram esse fato com base nas característica das marcenarias viçosenses, cuja produção é sob encomenda e se utiliza de máquinas simples e de baixa tecnologia. Ainda com relação ao comprometimento dos recursos naturais, os funcionários da marcenaria adotam algumas medidas para redução do consumo de energia, como, por exemplo, o aproveitamento da iluminação natural.

Com relação aos impactos relacionados ao meio antrópico, a geração de empregos caracterizouse como um impacto positivo. Embora a marcenaria estudada seja caracterizada como uma microempresa, segundo a classificação do Serviço Brasileiro de Apoio às Micro e Pequenas Empresas (SEBRAE) (2009), a atividade absorve um número razoável de mão de obra, pois a maioria das atividades é manual, 
isso devido à baixa tecnologia empregada, e, ademais, algumas fases da produção exigem um trabalho artesanal, criativo e minucioso. Ao contrário, os riscos de acidentes de trabalho devido à indisponibilidade e não uso de Equipamentos de Proteção Individual (EPIs) e às condições de insalubridade evidenciadas no local fez com que a maioria dos impactos relacionados ao fator antrópico fosse classificado como negativo. Segundo Silva et al. (2002), o trabalho na maioria das marcenarias viçosenses é realizado sob condições adversas à segurança e à saúde dos trabalhadores, ocasionando cansaço, dores nas pernas e na coluna, alergia devido à utilização de produtos químicos e ao pó da madeira, falta de treinamento para exercer a profissão e praticamente nenhuma noção sobre segurança e higiene no trabalho. Fiedler et al. (2008a) destacaram que o manuseio e a movimentação de cargas nas marcenarias ocasionam dor lombar nos trabalhadores, originando problemas crônicos e agudos que prejudicam a sua saúde e a eficiência do trabalho. Fiedler et al. (2008b) verificaram, também, que a carga física de trabalho foi classificada como medianamente pesada para todas as atividades.

Tabela 1. Identificação e caracterização qualitativa dos impactos ambientais da marcenaria por meio do Método da Matriz de Interação.

Table 1. Identification and characterization of the environmental quality of the woodwork by the Method of Matrix Interaction.

\begin{tabular}{|c|c|c|c|c|c|c|c|c|c|c|c|c|}
\hline \multirow[b]{4}{*}{$\begin{array}{l}\text { Atividades } \\
\text { impactantes }\end{array}$} & \multicolumn{12}{|c|}{ Fatores ambientais } \\
\hline & \multicolumn{6}{|c|}{ Meio físico } & \multicolumn{3}{|c|}{ Meio biótico } & \multirow{2}{*}{\multicolumn{3}{|c|}{ Meio antrópico }} \\
\hline & \multicolumn{3}{|c|}{$\mathbf{A r}$} & \multicolumn{2}{|c|}{ Solo } & \multirow[b]{2}{*}{ 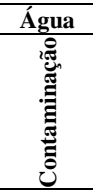 } & \multicolumn{2}{|c|}{ flora } & \multirow[b]{2}{*}{ 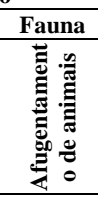 } & & & \\
\hline & 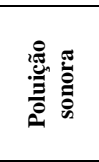 & 㺼 & 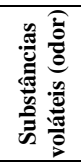 & 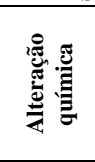 & 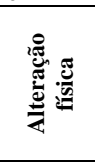 & & 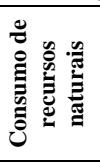 & 。 & & 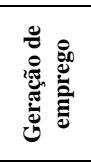 & 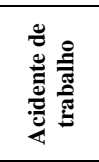 & 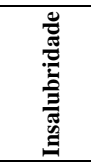 \\
\hline $\begin{array}{l}\text { Contratação de mão de } \\
\text { obra }\end{array}$ & - & - & - & - & - & - & - & - & NILOTV & PDLOYV & - & - \\
\hline $\begin{array}{l}\text { Aquisição da matéria- } \\
\text { prima }\end{array}$ & - & - & - & - & - & - & NDEOTV & NILMTV & - & - & - & - \\
\hline $\begin{array}{l}\text { Disposição da matéria- } \\
\text { prima }\end{array}$ & - & - & - & - & NDLMTV & - & NDEOTV & NDEOTV & - & - & NDLMTV & - \\
\hline $\begin{array}{l}\text { Funcionamento das } \\
\text { máquinas }\end{array}$ & NDLMYV & - & - & - & - & - & - & - & NDLOAV & - & - & NDLMYS \\
\hline $\begin{array}{l}\text { Processamento da } \\
\text { madeira pelo uso das } \\
\text { máquinas }\end{array}$ & NDLCYV & NILMTV & - & - & - & - & - & NILMTV & NDLOAV & - & - & - \\
\hline $\begin{array}{l}\text { Manutenção de } \\
\text { equipamentos e } \\
\text { reposição de peças }\end{array}$ & - & - & - & - & - & - & NDEOTV & - & - & - & - & - \\
\hline $\begin{array}{l}\text { Uso de produtos } \\
\text { químicos }\end{array}$ & - & - & NILCTV & - & - & - & - & - & - & - & - & NDLMYS \\
\hline $\begin{array}{l}\text { Aproveitamento das } \\
\text { sobras operacionais }\end{array}$ & - & - & - & - & - & - & PDEOTV & - & - & - & - & - \\
\hline $\begin{array}{l}\text { Descarte de resíduos } \\
\text { de madeira com } \\
\text { resquícios químicos }\end{array}$ & - & - & - & NDLMTV & NDLMTV & - & - & NDLMTV & - & - & - & - \\
\hline $\begin{array}{l}\text { Descarte de } \\
\text { embalagens }\end{array}$ & - & - & - & - & NDLMTV & - & - & - & - & - & - & - \\
\hline $\begin{array}{l}\text { Disposição dos } \\
\text { resíduos }\end{array}$ & - & - & - & - & NDLCYV & - & - & - & - & - & NDLMYS & NDLMYS \\
\hline Queima dos resíduos & - & NIRMTV & - & NILMYV & NDLMTV & - & - & - & NDLMTV & - & - & NDLMYV \\
\hline $\begin{array}{l}\text { Geração de efluentes e } \\
\text { resíduos domésticos }\end{array}$ & - & - & - & - & NDLCYV & NDRMTV & - & - & - & - & NDLCYV & \\
\hline
\end{tabular}

A classificação dos impactos ambientais obtida pela matriz de interação sugere que a solução para eles pode ser relativamente simples, já que na maior parte dos casos trata-se de impactos que ocorrem nas imediações do empreendimento, que cessam após um tempo determinado se interrompida a ação impactante e com possibilidade de o fator ambiental retomar às suas condições originais.

\section{Descrição dos impactos ambientais pelo método do "check list" e proposição de medidas mitigadoras e potencializadoras}

Encontram-se descritos na tabela 2 os principais impactos ambientais, listados segundo sua influência sobre os meios físico, biótico e antrópico, assim como as medidas mitigadoras e potencializadoras para os mesmos. Foram delineadas 36 medidas, a maioria mitigadora, sendo que sete delas se aplicam a mais de um impacto, ou seja, vários impactos podem ser mitigados ou potencializados adotando-se uma única medida. 
Tabela 2. Lista dos principais impactos ambientais e proposições de ações mitigadoras e potencializadoras.

Table 2. List of key environmental impacts and propose mitigation or amplify.

\begin{tabular}{l}
\hline Impactos ambientais \\
\hline Meio físico \\
\hline 1 - $\begin{array}{l}\text { Alteração da paisagem, devido à disposição inadequada dos } \\
\text { resíduos sólidos, tanto em áreas internas quanto externas da } \\
\text { marcenaria. }\end{array}$ \\
2 - Alteração da paisagem, devido à emissão de fumaça gerada \\
pela queima do pó de serra e resíduos de madeiras, \\
embalagens de produtos químicos e lixo doméstico. \\
3 - Alteração da paisagem, devido à emissão de pó de serra \\
gerado pelo processo produtivo da marcenaria. \\
4 - Alteração das propriedades do ar, devido à queima dos \\
resíduos de madeira a céu aberto. \\
5 - Alteração das propriedades do ar, devido à emissão de \\
materiais particulados provocado pelo processo produtivo da \\
marcenaria.
\end{tabular}

6 - Contaminação do solo, em consequência da queima de resíduos, tais como madeiras, produtos químicos, embalagens, latas e plásticos.

7 - Comprometimento da disponibilidade de energia elétrica, devido ao uso intensivo do maquinário no processamento e pela manutenção contínua de lâmpadas acesas durante o dia, devido à infraestrutura do galpão não permitir a entrada de luz solar suficiente.

Meio biótico queima dos resíduos a céu aberto.

2 - Afugentamento da fauna, devido à emissão de ruídos gerados no processo produtivo.

3 - Danos à vegetação, devido à emissão de materiais particulados, gerados pelo processo produtivo.

4 - Comprometimento da conservação dos recursos, em consequência da utilização de madeiras sem comprovação de procedência.
1 - Afugentamento da fauna, devido à fumaça emitida pela

Medidas mitigadoras ou potencializadoras

- Adequar a disposição dos resíduos, encaminhando-os para o local correto (aterro sanitário, incineração, reciclagem).

- Promover a coleta seletiva (instalação de lixeiras).

- Evitar a queima dos resíduos a céu aberto.

- Realizar a coleta seletiva do lixo doméstico.

- Utilizar os restos de madeira para a geração de energia.

- Encaminhar os resíduos do processo produtivo para granjas avícolas.

- Dar destino correto às embalagens de produtos químicos.

- Encaminhar o lixo doméstico para aterro sanitário.

- Instalar exaustores para a coleta do pó de serra.

- Não queimar os resíduos do processo produtivo a céu aberto. Incorporá-los diretamente ao solo e/ou destiná-los à compostagem.

- Instalar exaustores para a coleta do pó de serra.

- Realizar a coleta seletiva dos resíduos.

- Dar destino correto às embalagens dos produtos químicos (recolhimento e incineração)

- Não queimar os resíduos do processo produtivo a céu aberto. Incorporá-los diretamente ao solo e/ou destiná-los à compostagem.

- Melhorar a iluminação natural da marcenaria, mudando sua configuração, a fim de reduzir o consumo de energia.

- Uso de equipamentos mais eficientes no consumo de energia.

- Realizar manutenção periódica e preventiva dos equipamentos. - Treinar os funcionários para uso adequado dos equipamentos.

- Não queimar os resíduos do processo produtivo a céu aberto. Incorporá-los diretamente ao solo e/ou destiná-los à compostagem.

- Instalar a marcenaria em outro local, se possível.

- Instalar exaustores para a coleta do pó de serra.

- Uso eficiente dos recursos naturais.

- Utilizar madeira de origem comprovada e certificada.

- Priorizar o uso de madeiras de reflorestamento, painéis, compensados e MDF.

Meio antrópico

1 - Possíveis danos à capacidade auditiva dos funcionários, causada pelos altos níveis de ruídos emitidos pelas máquinas durante o processo produtivo.

2 - Comprometimento da saúde dos funcionários, devido à inalação do pó de serra e de produtos químicos, como colas fórmicas, vernizes e seladores, devido a não utilizarem frequentemente EPIs.

3 - Possíveis danos dermatológicos e oftalmológicos, devido à exposição direta aos produtos químicos e madeiras que possam causar reações alérgicas.

4 - Possível proliferação de doenças, em virtude da atração de moscas, ratos, baratas e escorpiões pelo acúmulo de resíduos.

5 - Probabilidade de ocorrência de acidentes, devido ao não cumprimento das medidas de segurança.

- Disponibilizar EPI's (protetor auricular) em quantidade suficiente para os funcionários.

- Fazer o uso adequado do EPI.

- Exigir e fiscalizar o uso do EPI.

- Disponibilizar EPI's (máscaras) em quantidade suficiente para os funcionários.

- Fazer o uso adequado do EPI.

- Exigir e fiscalizar o uso do EPI.

- Disponibilizar EPI's (máscaras, luvas, macacões de mangas longas, aventais, calçados fechados) em quantidade suficiente para os funcionários.

- Fazer o uso adequado do EPI.

- Exigir e fiscalizar o uso do EPI.

- Encaminhar os resíduos domésticos para aterro sanitário.

- Providenciar a limpeza das áreas adjacentes à marcenaria, como capina e roçada.

- Uso adequado dos EPI's.

- Treinar adequadamente os funcionários para operar equipamentos.

- Impedir o uso de certos equipamentos por funcionários não habilitados.

- Treinar funcionários para o uso de extintores de incêndios. 
Dentre as medidas delineadas, destacam-se, particularmente, aquelas relacionadas aos impactos gerados pela disposição inadequada dos resíduos do processo produtivo, das embalagens plásticas, vidros, latas e papéis, e aquelas que visam à manutenção da saúde e do bem-estar dos funcionários.

Com relação às medidas potencializadoras, destacam-se o incentivo ao programa de redução do consumo de energia e o encaminhamento dos resíduos de produção (que não sejam os resíduos químicos) para a geração de energia e para as granjas de frango, ressaltando que ambas as medidas já são adotadas pelos funcionários, mas irregularmente, ou seja, não ocorrem periodicamente, necessitando, portanto, de incentivos para a adoção de um programa regular de gerenciamento dos resíduos como um todo. Além dessas, destacam-se ainda outras medidas, tais como a escolha de matérias-primas menos impactantes ao meio ambiente, de materiais renováveis, a utilização de madeiras oriundas de reflorestamentos e certificadas, que tendem a contribuir diretamente para uma produção sustentável.

Visto se tratar de um empreendimento de pequeno porte, pode-se dizer que a adoção dessas medidas dependerá exclusivamente da decisão do proprietário da marcenaria. Por outro lado, considerando que a cidade de Viçosa está localizada nas proximidades do Polo Moveleiro de Ubá e que a atividade de marcenaria é bastante praticada no local, a associação desses proprietários é uma alternativa para se buscar a adoção de práticas ambientalmente corretas e que sejam economicamente viáveis para essa atividade. Exemplo disso ocorre no estado do Rio Grande do Sul, na indústria moveleira. Segundo Venzke e Nascimento (2002), a maioria das empresas desse setor está associada a uma fundação ou instituição que dispõe de um aterro industrial e de um sistema de gerenciamento de resíduos considerados modelos no estado do Rio Grande do Sul.

\section{CONCLUSÕES}

De acordo com os resultados deste trabalho, conclui-se que:

- a marcenaria estudada apresenta um número maior de impactos ambientais negativos do que positivos;

- a maior parte das atividades impactantes do empreendimento estudado foi classificada como Negativo, Direto, Local, de Médio Prazo, Temporário e Reversível (NDLMTV);

- os métodos de avaliação de impactos ambientais adotados mostraram-se eficientes para o empreendimento analisado, devido à facilidade de aplicação e complementaridade dos mesmos;

- as atividades impactantes da marcenaria estudada podem ser mitigadas ou potencializadas por meio de ações relativamente simples, já que seus impactos são, na maior parte dos casos, temporários e reversíveis;

- a adoção das medidas mitigadoras e potencializadoras delineadas depende, principalmente, da conscientização ambiental e da mudança de comportamento dos funcionários da marcenaria.

\section{REFERÊNCIAS}

ALVES, R. R.; CABRAL, C. P. T.; SOUZA, M. O. A.; VIDAURRE, G. B.; COLLI, A.; SILVA, J. C. Diagnóstico e caracterização das marcenarias na cidade de Viçosa, MG. Revista Semina, Londrina, v. 29, n. 4, p. 789 - 798, 2008.

ARRUDA, P. R. R. Avaliação qualitativa de impactos ambientais decorrentes de empreendimentos hidroelétricos. 117 f. Tese (Doutorado em Ciência Florestal) - Universidade Federal de Viçosa, Viçosa, 2000 .

BOVEA, M. D.; VIDAL, R. Materials selection for sustainable product design: a case study of wood based furniture eco-design. Materials and Design, n. 25, p. 111 - 116, 2004.

BRASIL. MINISTÉRIO DO MEIO AMBIENTE. Resolução CONAMA nº 001, de 23 de janeiro de 1986. Dispõe sobre as diretrizes e critérios da avaliação de impacto ambiental. Diário Oficial da União, Brasília, DF, 17 fev. 1986. Disponível em < http://www.mma.gov.br/port/conama/res/res86/res0186.html>. Acesso em 15/09/2011. 
BRITO, E. R.; SILVA, E.; MARTINS, S. V.; RIBEIRO, G. A. Perfil ambiental do empreendimento denominado de "praias fluviais", Estado do Tocantins. Árvore, Viçosa, v. 26, n. 3, p. 349 - 355, 2002.

COUTINHO, R. B. G.; SOARES, T. D. L. A. M. Gestão estratégica com responsabilidade social: arcabouço analítico para auxiliar sua implementação nas empresas no Brasil. Revista de Administração Contemporânea, Curitiba, v. 6, n. 3, p. 75 - 96, 2002.

FIEDLER, N. C.; WANDERLEY, F. B.; GUIMARÃES, P. P.; ALVES, R. T. Avaliação dos limites recomendados de pesos no manuseio de cargas em marcenarias. Revista Cerne, Lavras, v. 14, n. 2, p. 133 - 140, 2008a.

FIEDLER, N. C.; ALVES, R. T.; GUIMARÃES, P. P.; WANDERLEY, F. B. Análise da carga física de trabalho dos operadores em marcenarias no sul do Espírito Santo. Revista Floresta, Curitiba, v. 38, n. 3, p. $413-419,2008$ b.

LELLES, L. C.; SILVA, E.; GRIFFITH, J. J.; MARTINS, S. V. Perfil ambiental qualitativo da extração de areia em cursos d'água. Revista Árvore, Viçosa, v. 29, n. 3, p. 439 - 444, 2005.

MOREIRA, I. V. D. Avaliação de impactos ambientais. Rio de Janeiro: FEEMA/RJ. 1985. 34 p.

SERVIÇO BRASILEIRO DE APOIO ÀS MICRO E PEQUENAS EMPRESAS (SEBRAE). Critério de classificação das empresas. Disponível em: <http://www.sebrae.com.br〉. Acesso em: 05/07/2009.

SILVA, E. Avaliação qualitativa de impactos ambientais do reflorestamento no Brasil. 309 f. Tese (Doutorado em Ciência Florestal) - Universidade Federal de Viçosa, Viçosa, MG, 1994.

Técnicas de avaliação de impactos ambientais. Viçosa: CPT, 1999. 64 p.

SILVA, K. R.; SOUZA, A. P.; MINETTI, L. J. Avaliação do perfil do trabalhador e das condições de trabalho em marcenarias no município de Viçosa, MG. Árvore, Viçosa, v. 26, n. 6, p. 769 - 775, 2002.

VENZKE, C. S.; NASCIMENTO, L. F. O ecodesign no setor moveleiro do Rio Grande do Sul. Revista Eletrônica de Administração, Porto Alegre, v. 8, n. 6, p. 69 - 84, 2002. 